\title{
Resin Gingival Barrier as a Polymerizable Try-In Paste for Dynamic Try-In of Crowns and Veneers
}

Ahmed Abyad ${ }^{1}$ Ziad Jarrah ${ }^{2}$ Amin Hallak ${ }^{2}$ Hala Ragab² Essam Osman ${ }^{1}$

\begin{abstract}
Address for correspondence Ahmed Abyad, BDS, MSc, PhD, Department of Oral Rehabilitation Sciences, Faculty of Dentistry, Beirut Arab University Beirut Campus, Tarik El Jadida PO Box 11-50-20, Riad El Solh 11072809 Beirut, Lebanon (e-mail: a.abyad@bau.edu.lb).
\end{abstract}

Eur J Dent 2020;14:327-330
Abstract
Keywords
- ceramics
- crowns
- veneers
- try-in

Try-in sessions are often performed to check the fit and shape of restorations; however, try-in pastes do not exhibit enough viscosity to keep the restoration in place especially in the case of veneers that keep falling off during try-in. The use of polymerizable soft resins similar to those used as a gingival barrier in bleaching treatment can lock the veneer or crown in place during try-in for dynamic assessment of the restoration, at the same time easy removal of the paste is possible since the resin film is peeled off in one piece leaving no residues for cleanup.

\section{Introduction}

A try-in session is an important part of any esthetic rehabilitation case. It allows both the practitioner and the patient to assess the restorations in terms of fit, shape, and color. Statically, it is possible for the dentist to assess those parameters with regular try-in paste. However, it is reported in the literature that assessing the restorations dynamically when in function is an important process. ${ }^{1}$ During the try-in session, the patient should be able to evaluate the restorations when smiling and speaking. The dentist needs to assess these parameters to evaluate speech and esthetics. In addition, assessment of the occlusion prior to cementation should be performed to minimize post cementation adjustments in the ceramics. With regular try-in paste, these are not possible due to the low viscosity of most commercial try-in cements. This low viscosity causes the veneers to be dislodged immediately as the patient bites or performs any dynamic movement. For this reason, in most cases bite adjustments are still performed after cementation. This has a detrimental effect on the quality of the finalized restorations caused by loss of the high gloss layer on the surface of the ceramic material. Surface roughness and microcracks will develop on the surface due to adjustments performed after cementation. ${ }^{2}$ These adjustments often require subsequent intraoral polishing; However, the ceramic surface smoothness will not be on par with laboratory grade glaze. It is reported in the literature that surface microcracks will cause significant decrease in the strength of ceramic veneers, and therefore it is recommended that all bite adjustments to be performed during the try-in session to allow for a final laboratory glaze fire. ${ }^{3}$

Try-in pastes are fabricated with the primary concern that the optical properties of the paste should be identical to those of the cement. The viscosity and adherence power during the cementation are not given adequate attention by companies and the commercially available products are "water-runny" try-in pastes. Clinicians who utilize these try-in pastes experience the frustration of the crowns and more importantly veneers constantly falling off in the try-in session due to the low viscosity of the paste. Therefore, many clinicians attempt "non-academic" techniques for allowing the restorations to stay in place. These include the use of petroleum oil jelly "Vaseline" or other commercial nondental glue sticks such as "UHU." These practices have no basis in the literature and are used by clinicians at their own risk. Concerns should be raised regarding petroleum jelly due to the fact that these oils leave residues on the intaglio surface of the restorations that could adversely affect bonding. ${ }^{4}$ The disadvantage of using glue sticks "UHU," on the other hand, is their unestablished safety. These products were not intended for intraoral applications and their use for this purpose should be backed up by published evidence stating absence of cytotoxicity of such materials. Due to the preceding problems, the authors suggest the use of a polymerizable soft resin similar to that used 
as gingival dam material in bleaching treatments (Liquidam, Discus Dental; Philips Oral Healthcare, Stamford, CT, United States) (-Fig. 1). These resins are proven safe for intraoral use due to their long history in dental applications.5-8 In addition, these resins polymerize immediately and provide a soft interphase that locks the crowns or veneers in place, but makes removal an easy process with a dental explorer leaving no residues since the resin is removed as a single film (-Fig. 2).

\section{Case Report}

A 34-year-old patient presented to the outpatient clinic at Beirut Arab University seeking esthetic treatment. Patient's main concern was the multiple spacing and discoloration of the teeth. Medical and dental history was collected. Case was planned after radiographic and photographic assessment. Smile design was performed and patient had mock-up session prior to any preparation. After gaining approval from the patient, guided preparation was performed and veneers were fabricated. After verifying the fit of the restorations without any paste, the teeth were kept moist without excessive drying. One drop of Liquidam was placed on intaglio surface of the restorations. It was placed labially to avoid locking and facilitate easy removal. The crown or veneer was not filled

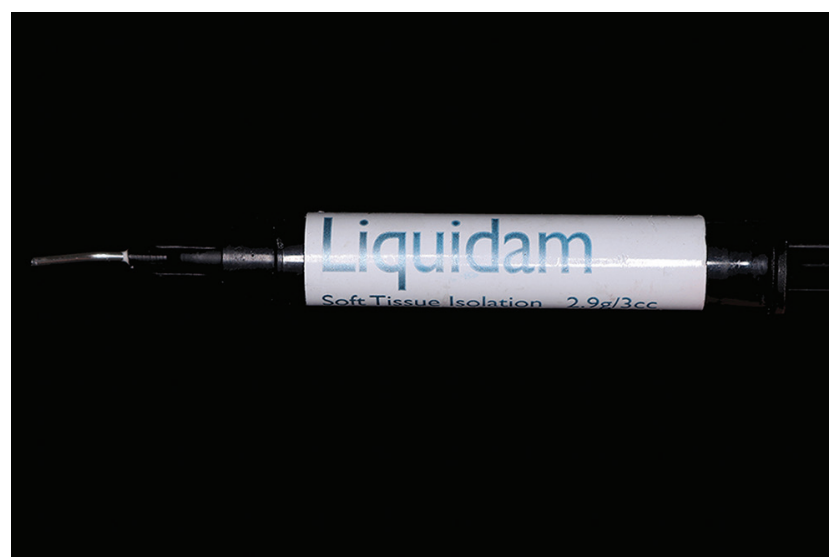

Fig. 1 Soft polymerizable resin (Liquidam).



Fig. 2 Frontal smile view of the patient. with Liquidam paste; only pea-sized drop was placed. The restorations were then placed with even pressure for complete seating and polymerized for 10 seconds using an LED curing unit. Dynamic try-in was performed and patient was asked to smile and talk without the fear of having the restorations fall off. Patient was asked to bite as well, and bite adjustments were performed. After completion of the try-in, the tip of a probe was inserted under the margin for removal. The Liquidam film was removed from the intaglio surface of the restoration as a single film (-Fig. 3). The intaglio surface was later sandblasted and cleaned with water and steam pressure.

\section{Discussion}

In this case, the ceramic utilized was monolithic lithium disilicate (IPS e.max CAD HT; Ivoclar-VivadentAG, Schaan, Liechtenstein) (-Fig. 4). The preoperative condition shows moderate discoloration and multiple spacing between the teeth ( - Fig. 2). Despite the nonretentive nature of the preparations ( $\mathbf{- \text { Fig. }}$ 5), the restorations did not fall off during the try-in due to the locking power of the Liquidam. Bite adjustment was also one of the prominent advantages in this technique since in traditional try-in, when the patient bites the restorations move out of place and therefore, most clinicians

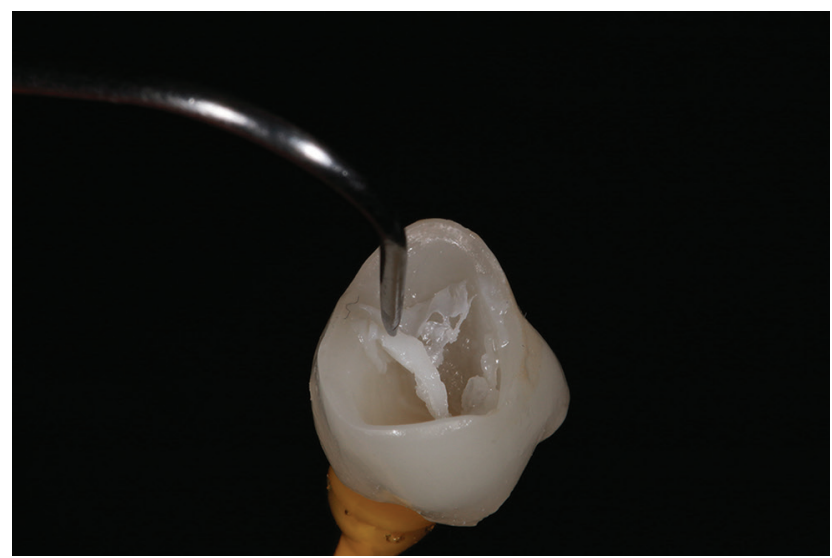

Fig. 3 Peeling off the Liquidam paste as a single film after try-in.

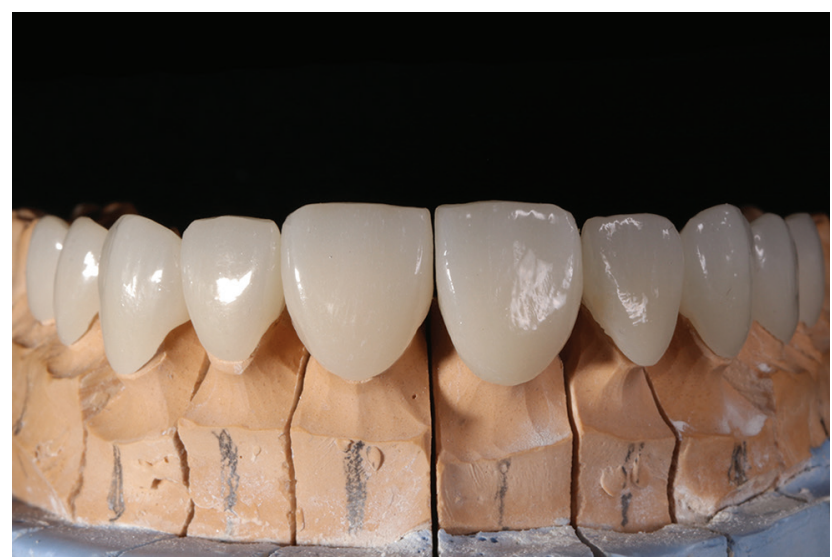

Fig. 4 Photograph showing the ceramic restorations used. 
keep the bite adjustments till after the cementation. This is not a recommended practice since it causes loss of the ceramic glazed surface, increases surface flaws, and decreases ceramic strength. ${ }^{9}$ Using this technique, occlusion marks left by articulating carbon paper were easily visualized on the cast and adjusted prior to final glaze because the restorations were not dislodged intraorally during dynamic try-in (-Fig. 6). Therefore, post-cementation bite adjustments are avoided. Patient was also able to smile wide, and pronounce various letters and practice speech allowing for the concept of dynamic try-in to be applied.

To compare the shade matching of traditional try-in paste and soft polymerizable resin, regular try-in paste was used in the left quadrant and Liquidam was utilized in the right quadrant to assess possible color differences ( - Fig. 7). Upon visual and electronic assessment using a clinical spectrophotometer (Easyshade V, VITA Zahnfabrik, Bad Sackingen, Germany), no color difference was recorded between the side with Liquidam and the side with regular try-in paste. For thinner ceramics, care must be taken as Liquidam might not replicate the optical properties of the cement used, notice the color difference between the regular try-in paste on the left and the Liquidam on the right ( $\boldsymbol{- \text { Fig. }}$ 8). In case of ultra-thin ceramics, it is recommended after the resin

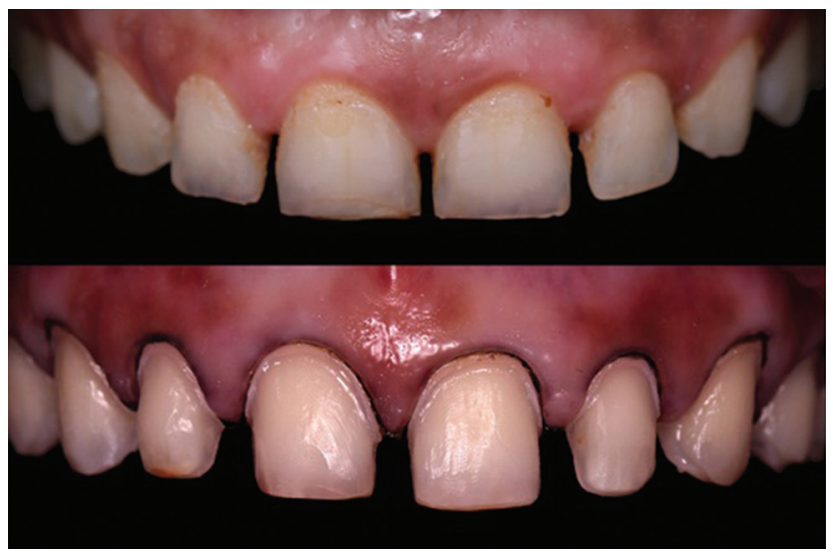

Fig. 5 Retracted view of teeth and respective preparations with retraction cord.

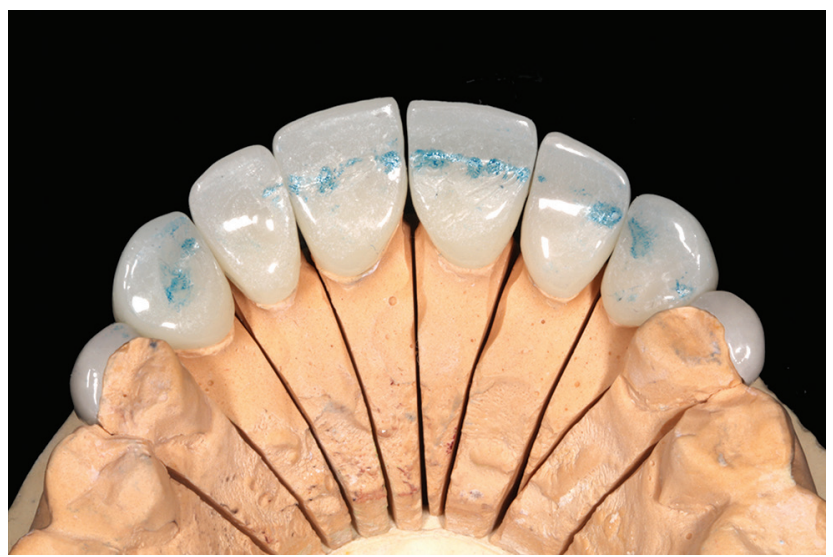

Fig. 6 Marks left by articulating paper after dynamic try-in of restorations. try-in to reconfirm color matching using a regular commercial try-in paste that is respective to the resin cement to be used for the final cementation. ${ }^{10}$ It could be arguable that the film thickness of Liquidam is higher than the try-in paste or the cement; This is clinically irrelevant at the try-in stage if there is complete seating of the restoration. The micron scale difference in film thickness plays an important role in the quality of the final cementation and the authors argue that it does not affect the fitting of the restorations during tryin. The seating could be confirmed using high magnification assessment of the margins of the restorations with a dental explorer under microscopes or utilizing macro dental photography. Despite of that, the advantages of using Liquidam for temporarily holding the restorations in place during tryin outweigh its limitation of use.

\section{Conclusion}

Soft polymerizable resin is useful for try-in of crowns and especially veneers lacking mechanical retention. Restorations fitted with Liquidam will not fall off during the try-in session as the patient smiles, speaks, or bites. It could be removed easily with the tip of a probe and the polymerized resin could be removed from the fitting surface as a single film without

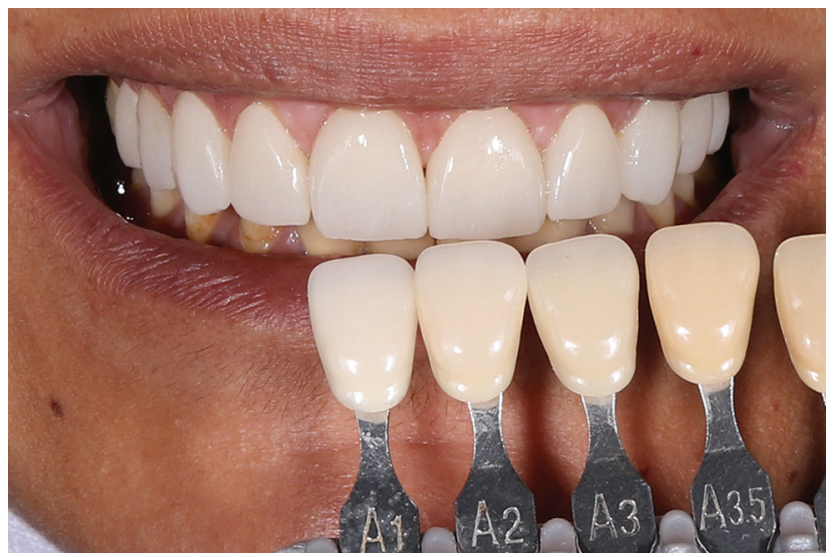

Fig. 7 Dynamic try-in of restorations showing regular try-in paste (left side) and Liquidam (right side).

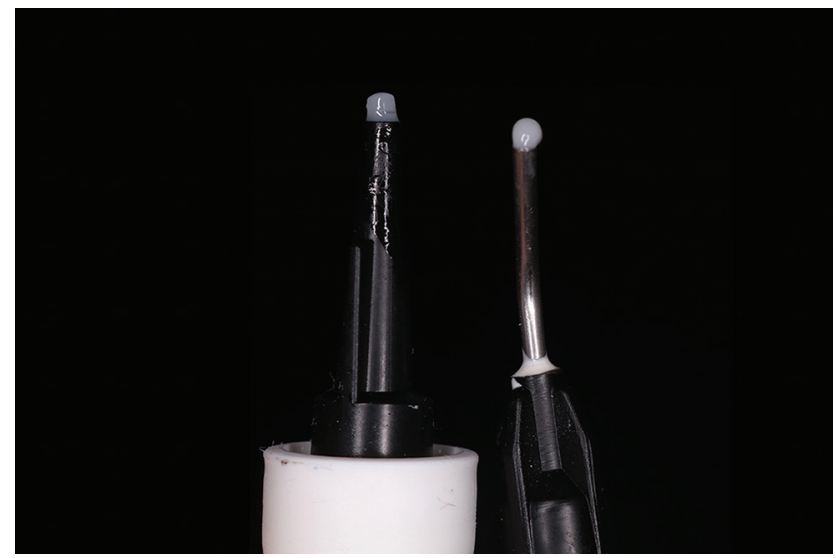

Fig. 8 Regular try-in paste left) (Liquidam to the right). 
leaving any residues. Care must be taken, however, with thin veneers for color reproducibility.

\section{Conflict of Interest}

Dr. Abyad reports grants from the National Council for Scientific Research (CNRS) during the conduct of the study. All the other authors report no conflict of interest.

\section{References}

1 Sarver DM, Ackerman MB. Dynamic smile visualization and quantification: Part 2. Smile analysis and treatment strategies. Am J Orthod Dentofacial Orthop 2003;124(2):116-127

2 Rashid $\mathrm{H}$. The effect of surface roughness on ceramics used in dentistry: a review of literature. Eur J Dent 2014;8(4):571-579

3 Linhares LA, Pottmaier LF, Lopes GC. Fracture resistance of veneers in premolars. Eur J Dent 2018;12(2):191-198
4 Matos AB, Oliveira DC, Vieira SN, Netto NG, Powers JM. Influence of oil contamination on in vitro bond strength of bonding agents to dental substrates. Am J Dent 2008;21(2):101-104

5 Fleisch AF, Sheffield PE, Chinn C, Edelstein BL, Landrigan PJ. Bisphenol A and related compounds in dental materials. Pediatrics 2010;126(4):760-768

6 Kong N, Jiang T, Zhou Z, Fu J. Cytotoxicity of polymerized resin cements on human dental pulp cells in vitro. Dent Mater 2009;25(11):1371-1375

7 Söderholm KJ, Mariotti A. BIS-GMA--based resins in dentistry: are they safe? J Am Dent Assoc 1999;130(2):201-209

8 Gupta SK, Saxena P, Pant VA, Pant AB. Release and toxicity of dental resin composite. Toxicol Int 2012;19(3):225-234

9 Fairhurst CW, Lockwood PE, Ringle RD, Thompson WO. The effect of glaze on porcelain strength. Dent Mater 1992;8(3):203-207

10 da Cunha LF, Reis R, Santana L, Romanini JC, Carvalho RM, Furuse AY. Ceramic veneers with minimum preparation. Eur J Dent 2013;7(4):492-496 